\title{
THERMAL MAPPING IN FLAT LOWLANDS AND UNDULATING UPLANDS - A COMPARISON OF RESULTS
}

\author{
LAURYNA ŠIDLAUSKAITE் ${ }^{1 *}$, JÖRGEN BOGREN² \\ ${ }^{1}$ Institute of Geosciences, Vilnius University, Vilnius, Lithuania \\ ${ }^{2}$ Dept of Earth Sciences, Gothenburg University, Gothenburg, Sweden
}

Received 08 February 2019; accepted 29 May 2019

\begin{abstract}
Thermal mapping has been known as a reliable technique to analyse and even predict road surface temperature in a stretch of road, rather than just a single point (e.g. road weather station location). The method itself was developed in the 1980s, and as time progressed, the technique was improved and has become more applicable. Due to other methods, such as climate modelling, becoming widely accessible and more affordable to apply, thermal mapping started being pushed out to the background as an expensive alternative. The idea for this paper arose from thermal mapping applications to Lithuanian roads that produced inconclusive results in some research areas and raised the question of whether this technique applies to flatlands as effectively as to uplands. The Czech Republic was chosen as a country with an available database and environmentally different road network. Several stretches of road thermal mapping data were analysed and compared. It was concluded, that in flat landscapes altitude has lesser predictability value for road surface temperature than in undulating uplands. In addition, thermal mapping results appear to be more inconclusive in flatlands, compared to uplands. Nevertheless, thermal mapping is a good and reliable method for determining cold spots.
\end{abstract}

Keywords: mapping technique, road climatology, road surface temperature, road weather station, road weather, thermal mapping.

* Corresponding author. E-mail: lauryna.sidlauskaite@chgf.vu.lt

Lauryna ŠIDLAUSKAITĖ (ORCID 0000-0001-7753-29511)

Jörgen BOGREN (ORCID 0000-0001-6322-64862)

Copyright (C) 2019 The Author(s). Published by RTU Press

This is an Open Access article distributed under the terms of the Creative Commons Attribution License (http://creativecommons.org/licenses/by/4.0/), which permits unrestricted use,

distribution, and reproduction in any medium, provided the original author and source are credited. 


\section{Introduction}

Regions with ice and snow during winters are dependent on microclimate conditions of roads, since cleaning, de-icing and treating the network is financially expensive and time-consuming. Failing to do this effectively can result in increased traffic vulnerability to accidents and financial loss (Andreescu \& Frost, 1998; Norrman, Eriksson, \& Lindqvist, 2000; Usman, Fu, \& Miranda-Moreno, 2010). Moreover, ineffective overuse of salts and other treatment compounds can have various adverse effects on pavements and the environment (Cunningham, Snyder, Yonkin, Ross, \& Elsen, 2008; Fay \& Shi, 2012; Hassan, Abd El Halim, Razaqpur, Bekheet, \& Farha, 2002; Howard \& Haynes, 1993). Therefore, various methods of measurement, data assessment, and forecasting of road surface temperature and condition have been developed since the 1980s. This advance in technology helped to decrease maintenance personnel reaction time to weather events and even apply preventive measures against ice formation. Over the years, Road Weather Information Systems (RWIS) with networks of automatic meteorological stations on roads provide continuous one-dimensional meteorological data on road microclimate, and in combination with twodimensional road thermal mapping data, this information is used as an initial base of future road conditions forecasting (Chapman, Thornes, \& Bradley, 2002a, 2002b; Chapman \& Thornes, 2006). The technology of Road Weather Information System (RWIS) has been applied to various regions around the world and is continuing to be the main source of every-day information about road weather conditions.

Thermal mapping technique was first introduced to road climatology as an idea in the middle 1970s, but best described and applied to research after 15-20 years (Bogren \& Gustavsson, 1989, 1991; Thornes, 1991). Since then the technique was improved and re-evaluated (Gustavsson, 1999; Shao \& Lister, 1995; Shao, Lister, Hart, \& Pearson, 1996; Shao, Swanson, Patterson, Lister, \& McDonald, 1997), to minimize the possibility of errors and increase the quality of data received using this method. The technique relies on the fact that "cold" sections of the road remain colder and "warm" sections remain warmer than average during different weather conditions. Thermal mapping involves route surveillance that is performed during several winter nights using vehicle-mounted IR thermal sensors and GPS technology. Usually, two categories of weather are considered and aimed for: extreme - clear and calm nights with no significant wind present, and damp - cloudy or overcast nights, which can be windy. In some cases, a third category is also surveyed - intermediate - that describes conditions between the first two.
Thermal Mapping

in Flat Lowlands

and Undulating

Uplands -

a Comparison

of Results 
Traditionally, thermal mapping was used before installing RWIS meteorological stations to detect locations that have different temperature patterns compared to neutral or average areas. Whereas today, when IR sensors and GPS became widely available and affordable, this technique is often applied after RWIS stations have already been installed too. The reason for this is either to check how temperature patterns have changed after pavement reconstruction or, lacking it, to install new additional stations, to use the data for forecasting models.

Many factors can affect road surface and increase the difference between road and air temperatures, which results in considerable cooling of roads in some areas, while others remain relatively warm. It is widely documented, that one of the main factors is the relative altitude of a road and its surrounding area: surface depressions can form cold air pools during clear and calm nights. Development of cold air pools is forced by a downslope flow of cold air into surface depressions and valleys, local radiative cooling, or a combination of both (Gustavsson, Karlsson, Bogren, \& Lindqvist, 1998). This phenomenon can form in valleys of various sizes (Vosper \& Brown, 2008; Whiteman, Haiden, Pospichal, Eisenbach, \& Steinacker, 2004), develop strong temperature inversions (Clements, Whiteman, \& Horel, 2003; Vitasse, Klein, Kirchner, \& Rebetez, 2017), and in some areas, remain for long periods of time (Whiteman, Zhong, Shaw, Hubbe, Bian, \& Mittelstadt, 2001).

Nevertheless, altitude is not the only cause for temperature drops, especially where it is not the main aspect in the formation of a landscape. Forest canopy configuration (Kiefer \& Zhong, 2015), different radiative effectiveness of various or inconsistent pavements (Mirzanamadi, Johansson, \& Grammatikos, 2018), and sky-view factor (Bogren, 1991; Bradley, Thornes, Chapman, Unwin, \& Roy, 2002; Hu, Almkvist, Lindberg, Bogren, \& Gustavsson, 2016) have the highest influence on road pavement temperature besides the relative altitude.

The idea for this paper arose from thermal mapping applications to Lithuanian roads that produced inconclusive results in some research areas and raised the question of whether this technique applies to flatlands as effectively as to uplands. The collected thermal mapping data was intended for the development of the winter maintenance decision support system in Lithuania but was not used since then. The data showed that distinctive temperature anomalies could still be observed in some specific places (e.g. negative temperature anomalies on bridges and overpasses) and short stretches of road; otherwise, it seemed that there were no significant patterns connected to altitude in the whole route as expected beforehand. To determine the cause for this, a comparison between different areas needed to be done, therefore 
a second country with available reliable thermal mapping database was chosen - the Czech Republic. In this approach, the scope of temperature changes and patterns, and potential predictability in chosen the Czech Republic roads were evaluated, then applied and compared to Lithuanian in Flat Lowlands and Undulating Uplands a Comparison of Results roads.

Both the Czech Republic and Lithuania have similar weather patterns, but Vilnius (Lithuania) has colder winters with more precipitation compared to Prague (the Czech Republic): with average monthly temperature in Vilnius being about $2-3{ }^{\circ} \mathrm{C}$ lower than in Prague, and the average sum of precipitation is higher by $18-25 \mathrm{~mm} / \mathrm{mo}$. However, the main difference among the countries is the altitude. The stretches of roads used in this study from the Czech Republic are situated between $277 \mathrm{~m}$ and $547 \mathrm{~m}$, whereas from Lithuania - only 7-202 $\mathrm{m}$ above sea level and the average change of altitude between the data points is $0.47 \mathrm{~m}$ and $0.34 \mathrm{~m}$, respectively.

This paper aims to discuss whether thermal mapping can be as effective in lowlands as in mountainous or hilly regions, taking the Czech Republic and Lithuania as two examples on the opposite sides.

\section{Data and methods}

There were several datasets used in this study. Firstly, there was thermal mapping data from the Czech Republic, which was collected during the winters of 2012-2017. After the initial evaluation, two road sections were chosen:

- section CZ1 in motorway No. 18 (from Olbramovice to Př́íbram), and

- section CZ2 in motorway No. 19 (from Tabor to Lety).

Both sections were measured 3-4 times during extreme, and once during damp conditions.

Thus, only some parts of datasets from 2015 were used. All sections are $45-50 \mathrm{~km}$ in length, relatively straight, and do not contain significant interchanges. CZ1 and CZ2 were chosen for them being in a mountainous region, and the elevation changing rapidly and continuously along the route.

Secondly, there was thermal mapping data from Lithuania, which was collected during January and February of 2015. Because of differences in the type of roads that were measured, the whole dataset was divided into four major sections (some interchanges and other similar parts of the route being omitted):

- LT1 - motorway A2 Vilnius-Panevėžys (from Vilnius to Panevėžys); 
- LT2 - motorway A17 Panevėžys Passway and main road E67 Helsinki-Tallinn-Riga-Panevėžys-Kaunas-Warsaw-WrocławPrague (from Panevėžys to Saločiai);

- LT3 - motorway E67 Helsinki-Tallinn-Riga-Panevėžys-KaunasWarsaw-Wrocław-Prague (from Panevėžys to Kaunas);

- LT4 - motorway A5 Kaunas-Marijampolè- Suwałki and main road E67 Helsinki-Tallinn-Riga-Panevėžys-Kaunas-WarsawWrocław-Prague (from Kaunas to Kalvarija).

These sections varied in length - from $78 \mathrm{~km}$ to $118 \mathrm{~km}$ but were also relatively straightforward. Initially, Lithuanian roads were measured during three different conditions: clear (equivalent to the extreme), intermediate, and overcast (equivalent to damp). The intermediate conditions were not used in this study. In addition, after the initial evaluation, LT2 measurements were eliminated from the analysis because of apparent technical issue and inconsistent data. The altitude was not measured; therefore, the required data was derived from Lithuanian georeferenced database (acronym - GDR10LT). Thus, this data does not reflect the absolute altitude of a road but rather represents the average absolute altitude for the area around it.

Ordinary Kriging interpolation method (with spherical semivariogram model) was used to match data points from different measurements along the routes for both the Czech Republic and Lithuanian datasets. This process also filtered the data, emitting some of the unnecessary noise. Data filtering is essential in thermal mapping, and several methods can be used (Shao \& Lister, 1995). For this study, an interpolation of values along the routes performed well (most importantly, the mean of the datasets did not change significantly) and allowed for easily comparable dataset creation. The road sections were divided into multiple short segments, each being 25 meters in length, and data values were extracted at every segment end.

At this point, various statistical parameters were calculated using thermal mapping and other spatial data from georeferenced databases. The roads were divided into depressions to evaluate the landscape changes along the routes, i.e. segments confined by two relative peaks in altitude and only those that are at least $1 \mathrm{~m}$ deep were considered. In addition, a percentage of the route was calculated where cold air pooling might have taken place:

$$
\text { cap }=\frac{l_{\text {cap }}}{l} 100 \%,
$$

where $l_{\text {cap }}$ - length of route part that fit the requirements: where the road was colder than air and moving correlation $( \pm 0.5 \mathrm{~km})$ between road temperature and altitude was +0.8 or above (extreme conditions), $\mathrm{km}$; 
$l$ - full length of the route, $\mathrm{km}$. Note: both $l_{\text {cap }}$ and $l$ must be in the same or in Flat Lowlands any of length units.

An area with a radius of $0.5 \mathrm{~km}$ around the segment point was chosen for continuous parameter evaluation since local surroundings have the highest impact on road weather during extreme conditions. For dichotomous parameters, an area with a radius of $25 \mathrm{~m}$ around the road was chosen. Pearson correlation coefficient was used for continuous datasets and point biserial correlation coefficient for when one dataset was dichotomous to assess the association between the parameters. Correlation coefficients presented in this paper are all statistically significant when .

\section{Results}

The chosen routes (CZ1 and CZ2) have a similar set of depressions (Table 1) with a median change of 16-18 $\mathrm{m}$ in altitude, some reaching 66-128 m. In addition, the depressions in the Czech Republic routes usually have a width of more than $1 \mathrm{~km}$, some reaching 4-5 km. On the other hand, the median change of altitude in Lithuanian routes is only

Table 1. General statistics of altitude depressions

\begin{tabular}{|c|c|c|c|c|c|}
\hline Route ID & CZ1 & CZ2 & LT1 & LT3 & LT4 \\
\hline \multicolumn{6}{|c|}{ Depression count } \\
\hline Sum & 18 & 19 & 127 & 42 & 70 \\
\hline \multicolumn{6}{|c|}{ Maximum change in elevation $(D)$, meters } \\
\hline Average & 29.5 & 22.4 & 6.7 & 4.5 & 4.3 \\
\hline Median & 18.0 & 16.0 & 3.0 & 3.0 & 2.0 \\
\hline Minimum & 1.2 & 1.1 & 2.0 & 2.0 & 2.0 \\
\hline Maximum & 127.7 & 65.9 & 113.0 & 15.0 & 45.0 \\
\hline \multicolumn{6}{|c|}{ Width of the depression $(W)$ along the route, meters } \\
\hline Average & 2295.8 & 1943.4 & 258.5 & 231.0 & 199.3 \\
\hline Median & 1862.5 & 1425.0 & 175.0 & 150.0 & 137.5 \\
\hline Minimum & 925.0 & 500.0 & 50.0 & 75.0 & 50.0 \\
\hline Maximum & 5125.0 & 4375.0 & 1000.0 & 950.0 & 875.0 \\
\hline \multicolumn{6}{|c|}{ Ratio $\left(\frac{W}{D}\right)$} \\
\hline Average & 367.9 & 263.1 & 67.7 & 69.1 & 75.0 \\
\hline
\end{tabular}

Note: depression - where a change in elevation is more than $1 \mathrm{~m}$ 
2-3 $\mathrm{m}$ and the width of the depression does not exceed $1 \mathrm{~km}$, usually staying shorter than $150-160 \mathrm{~m}$.

For an area as mountainous as the Czech Republic, it is expected to observe cold air pooling in some surface depressions during extreme weather conditions. The chosen routes reflected this to some degree: the overall averaged difference between temperatures in depressions and peaks is $-0.78{ }^{\circ} \mathrm{C}$ for air temperature and $-0.25^{\circ} \mathrm{C}$ for road surface temperature (negative difference meaning the road surface is colder than air). The difference between road and air temperature is higher by $0.52{ }^{\circ} \mathrm{C}$ on average in depressions. Nevertheless, not every depression can form cold air pools since roads might not go through the lowest part of the valley, and the depressions themselves might not be "bowl" shaped. Therefore, statistically significant correlation coefficients between an altitude of depression and corresponding air temperature at the lowest point of depression are not high (0.20 in CZ1 and 0.49 in $\mathrm{CZ2}$, on average and during extreme conditions), but are in a consistent pattern between CZ1 and CZ2. Moreover, the higher it gets, the rarer it is for the road to be colder than air. This tendency is similar in both stretches of road, the correlation between altitude and temperature difference of road surface and air temperatures (on average) during extreme conditions being: -0.35 for depressions and -0.49 for peaks in CZ1; -0.35 for depressions and -0.59 for peaks in CZ2.

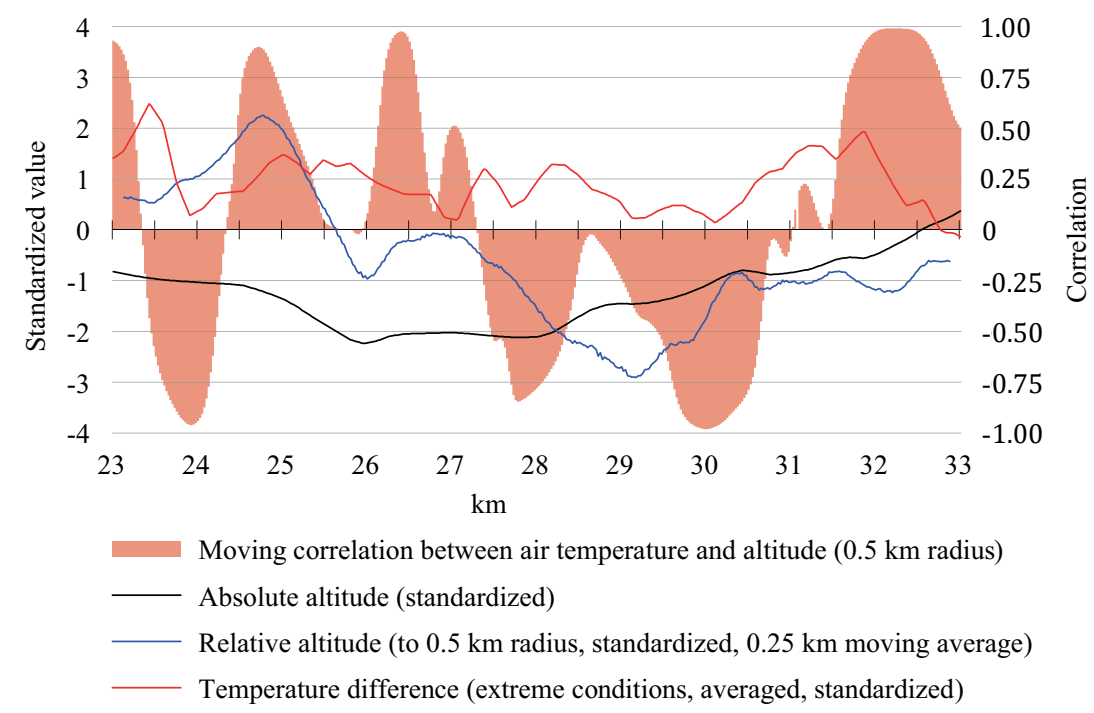

Figure 1. An example of a set of parameters in a route in the Czech Republic 
Air temperature relation to altitude is uneven across the roads. in Flat Lowlands and Undulating Overall correlation gives moderate results: on average, a positive correlation on both roads is 0.50-0.52 and 0.48-0.66 (CZ1 and CZ2 respectively). In those stretches where there is a relatively steep slope, moving correlation (radius of $0.5 \mathrm{~km}$ around the segment point) drops to zero, and in some places reverts to negative. One of the best examples of this is shown in Figure 1, where the lowest points in altitude are plains of Vltava and Brzina rivers. In this example, in areas where

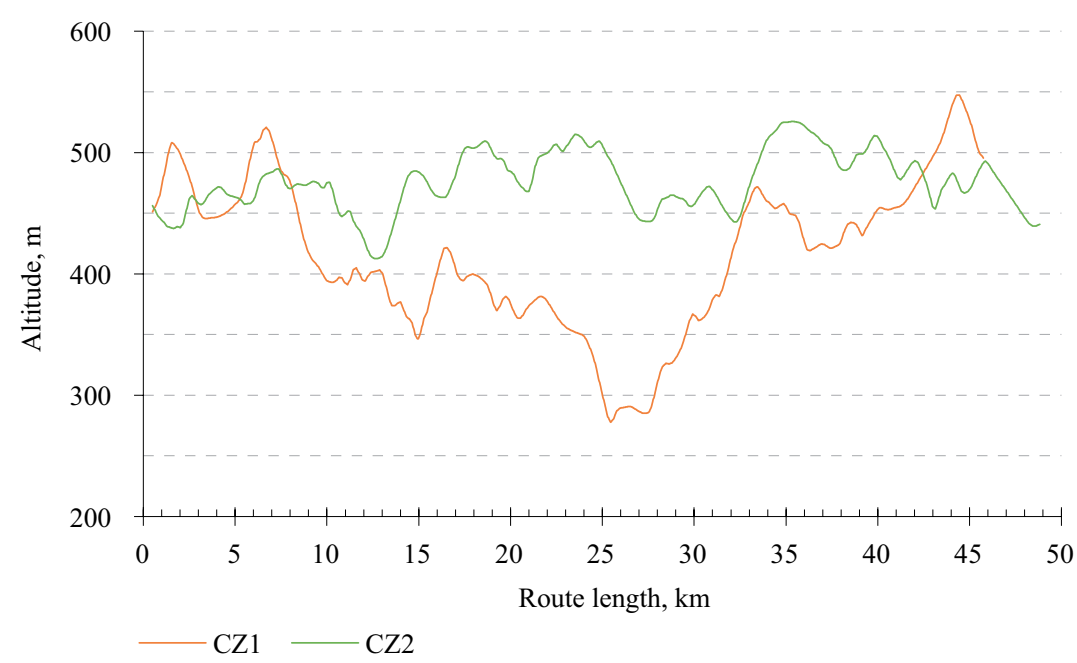

a) altitude of thermal mapping routes (CZ1-CZ2)

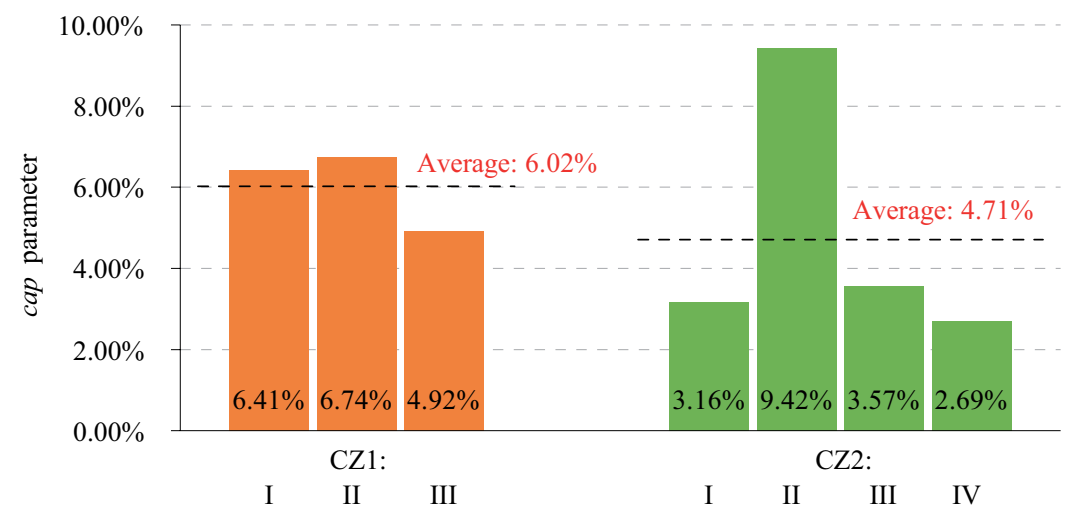

b) cap (Eq.) parameter in the same routes during different measurement events (I-IV)

Figure 2. Comparison of altitude and cap parameter in the Czech Republic 
the relative altitude of the road (compared to an average with a radius of $0.5 \mathrm{~km}$ around the road) changes considerably, moving correlation drops from strongly positive to weak, and even to strong negative. Conversely, in areas where relative altitude change falls within overall noise range or changes insignificantly, the relationship is strong and positive. This variation suggests that the strength of air temperature relation to altitude is essentially dependent on whether the area is relatively flat or has an incline, while air temperature could be partially predicted by relative altitude in former areas, but the latter would have a lower rate of predictability.

CZ1 and CZ2 gave different results as well. CZ1 has less variation in absolute height, with highest peaks being at the ends of the route and several larger valleys in between but have the highest peaks and lowest depressions in both road stretches (Figure 2a, absolute height varies between $277 \mathrm{~m}$ and $547 \mathrm{~m}$ ). Whereas in CZ2 elevation varies more, continually switching between peaks and depressions, but has a lower absolute height (Figure 2a, absolute height varies between $413 \mathrm{~m}$ and $526 \mathrm{~m}$ ). Using average measurement data during extreme conditions, only $6.0 \%$ of CZ1 and $4.7 \%$ of CZ2 had favourable conditions for cold air pooling effect of taking place (cap parameter, Eq., Figure 2b). The variation (amplitude) of this index on different measurements in extreme conditions is greater in CZ2 than in CZ1: $6.7 \%$ and $1.8 \%$ respectively. This difference formed because of one of the measurements, during which the index reached a high percentage (Figure 2b, II measurement reached 9.4\%), while during others it stayed similar $-3.17 \%$ on average. It might have happened because of the conditions being extremely favourable on that particular night, and the index value thus became exceptionally high.

CZ1 route has lengthier slopes than CZ2, and depressions, there are relatively wider (Table 1). This unevenness might be the cause for cap parameter (on average). More significant depressions with steep slopes have a higher chance of semi-vertical air movement, provided there are no significant obstacles or other objects limiting the flow. In addition, it is expected to have higher temperature differences in landscape points with more considerable altitude change. Therefore, by this data, it is expected that a flatter area has less predictability value than one with a more undulating and changing landscape.

Data from Lithuanian thermal mapping shows different results. Correlation between temperature difference (road surface temperature minus air temperature) and altitude during extreme conditions during different measurement events on the same roads was not consistent. For example, a twice measured LT1 road (during the same night) had correlation coefficients of -0.55 and +0.23 (on average). This variance 
Thermal Mapping

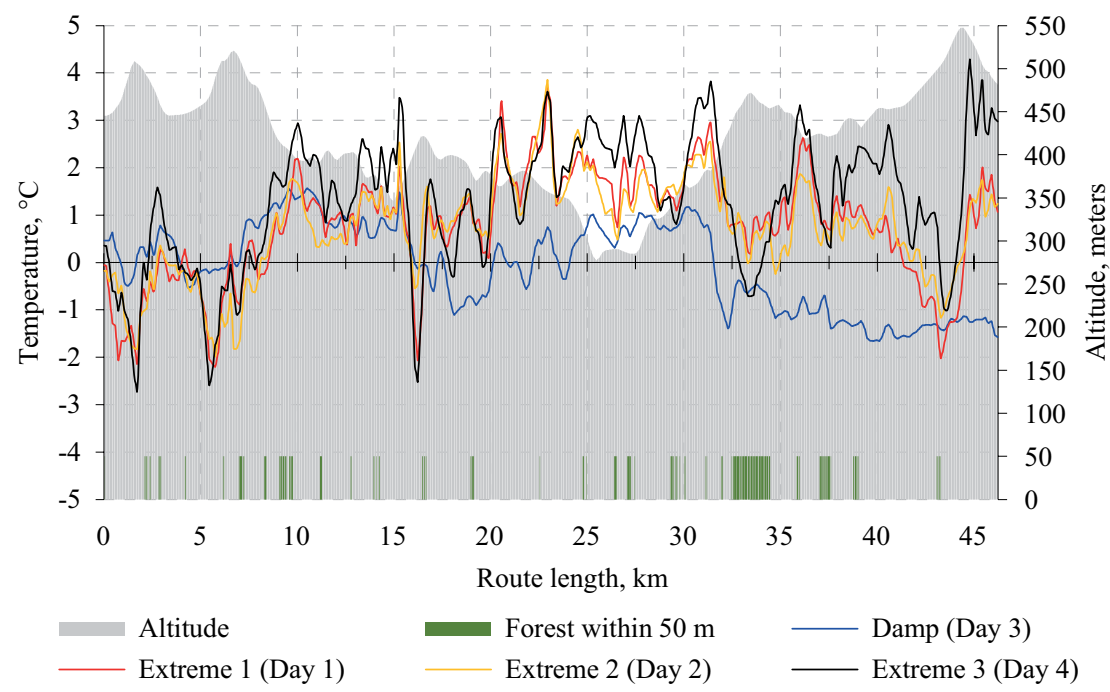

in Flat Lowlands

and Undulating

Uplands -

a Comparison

of Results

a) route $\mathrm{CZ1}$ in the Czech Republic

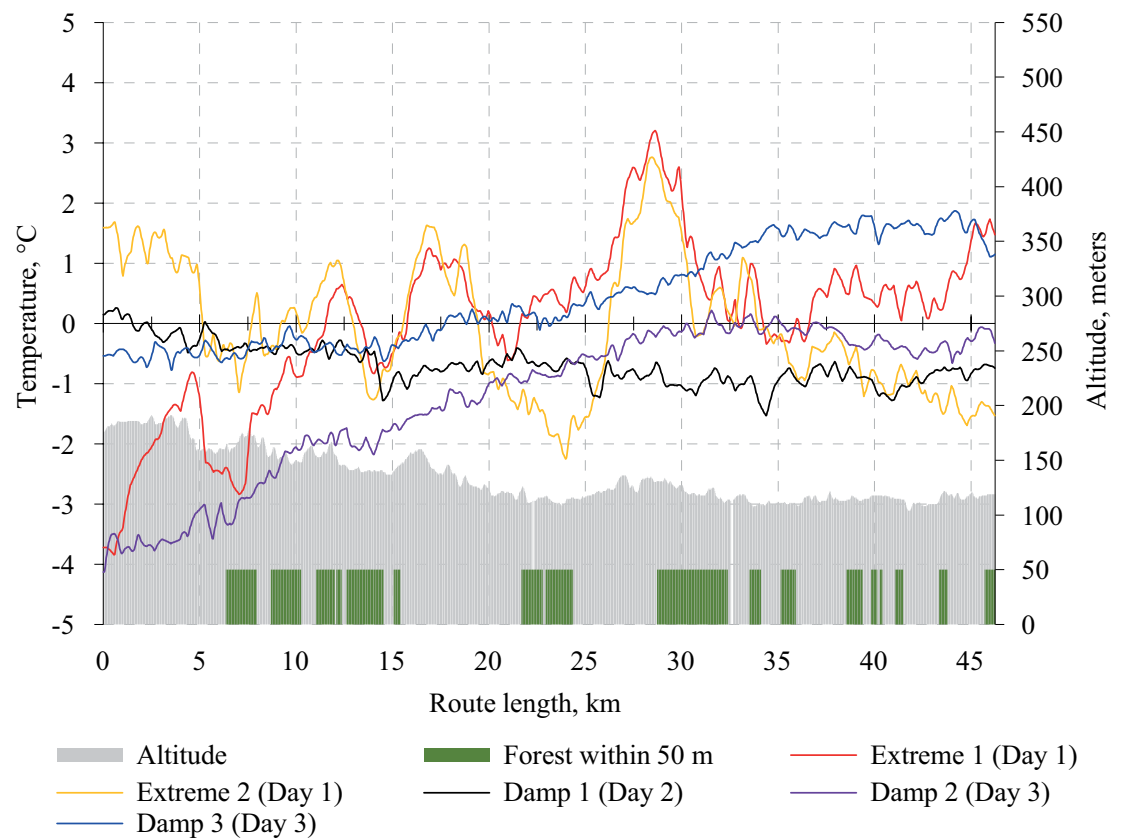

b) part of route LT1 in Lithuania

Figure 3. The temperature difference between the road surface and air 
suggests that cold air pooling might not take place concerning the weather in the area being more influenced by other variables, rather than changes in altitude. It is also noticeable in an example given in Figure 3, where the Czech Republic road surface temperature clearly

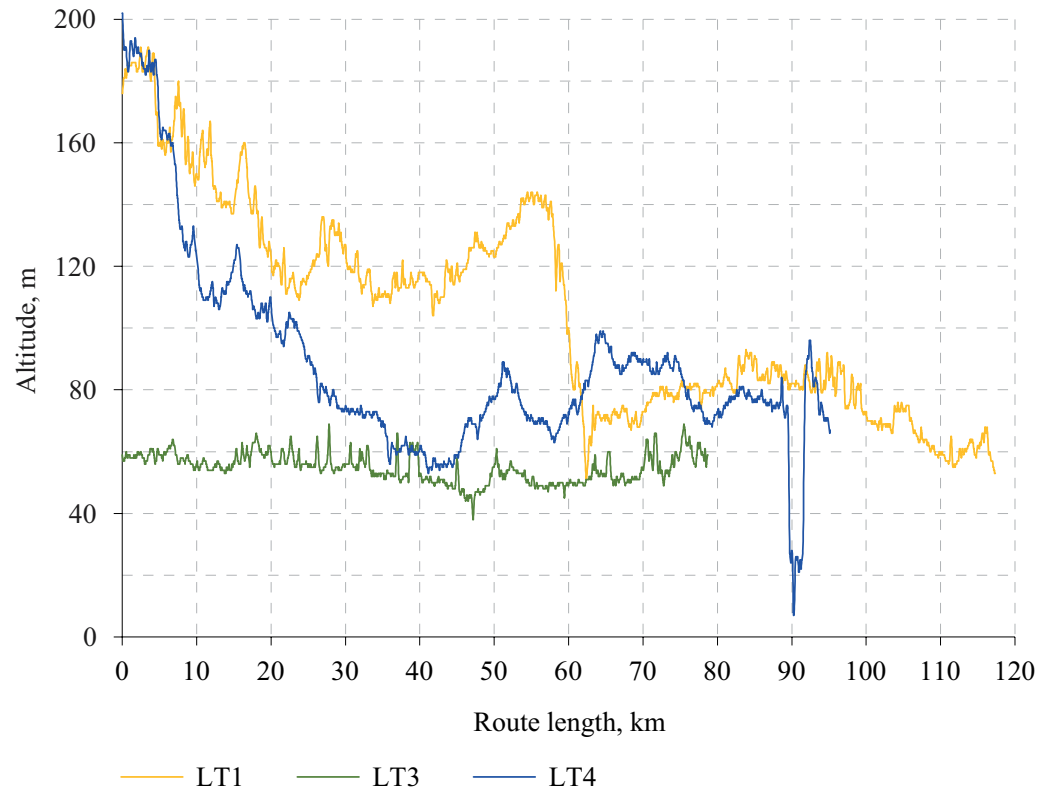

a) altitude of thermal mapping routes (LT1-LT4)

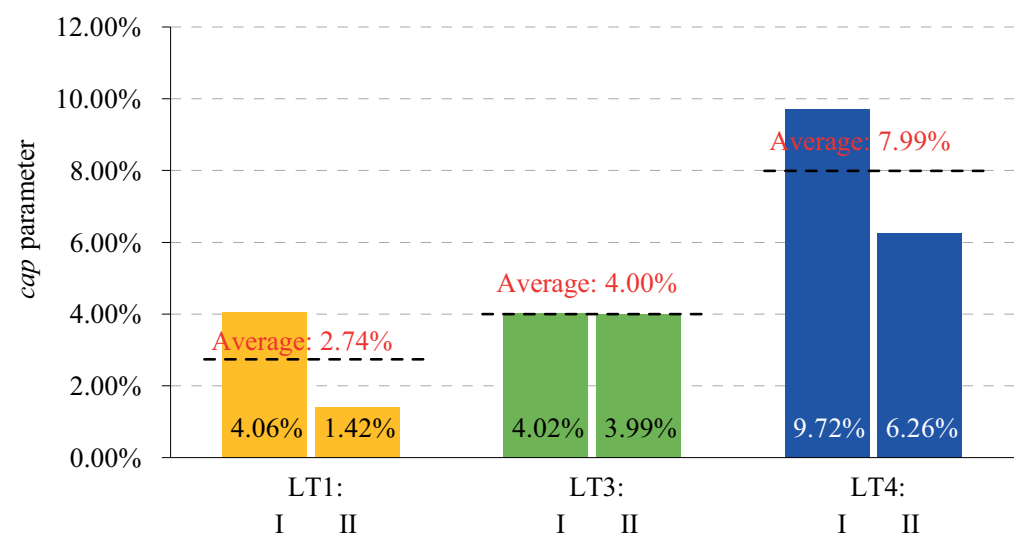

b) cap (Eq.) parameter in the same routes during different measurement events (I-II)

Figure 4. Comparison of altitude and cap parameter in Lithuania 
and closely follows the altitude changes, but in Lithuanian road temperature changes are in variance with altitude. Moreover, there is no resemblance between measurements in extreme and damp conditions in Lithuania, whereas in the Czech Republic the line spikes are all similar. in Flat Lowlands and Undulating Uplands a Comparison In addition, Lithuanian landscape slopes are extremely gradual, and depressions are very shallow, compared to the Czech Republic roads. Therefore, the semi-vertical airflow velocity is low and cold air pooling requires favourable conditions to prevail for a more extended period, one night usually being insufficient.

Nevertheless, the cap parameter (Eq.) variation is similar to the Czech Republic roads. LT1 and LT4 routes have a more changing landscape, where one end is about $200 \mathrm{~m}$ in altitude, another - between $60 \mathrm{~m}$ and $80 \mathrm{~m}$, while LT3 - is relatively flat, about $60 \mathrm{~m}$ above sea level (Figure 4a). Both measurement events in one route were done during the same night but at different times (Figure $4 \mathrm{~b}$, II being later than I). The index varied from $1.42 \%$ to $9.72 \%$ between different road stretches and different measurement events in extreme conditions. In all three cases, the cap parameter was both increasing as the night progressed and more stable in areas where the landscape was flatter.

\section{Discussion}

In conclusion, it appears that in flat landscapes altitude has less predictability value for road surface temperature than in undulating uplands. Former areas are being more influenced by advancing air masses and general weather changes rather than local landscape. In addition, thermal mapping results appear to be more inconclusive in flatlands, compared to uplands. Nevertheless, there are still some cases in Lithuanian roads, for example, where road temperature consistently dropped lower than air during most of the measurement events. Therefore, thermal mapping is still a valid method for determining such cold spots. It seems that thermal mapping must be done in perfect extreme conditions to get good results. Therefore, this causes additional difficulties when choosing the right night in a climate such as one in Lithuania, since clear and calm nights can be a rarity on a particular season when the surveillance is planned.

Usage of such temperature difference maps for road temperature forecasting is becoming questionable. Since there is a high chance of getting inconclusive results, and the method is quite expensive to apply, thermal mapping appears to be an inefficient way to determine thermal road features in flatlands. Nevertheless, when applied correctly, this method remains an accurate way to evaluate thermal differences 
caused by the geographical environment of the road. Technological advancements and expanding availability of computing resources provide a significantly less costly and more consistent approach with numerical modelling, open data sources. Constant development and innovation bring road temperature forecasting to a more efficient and accurate era.

\section{Conclusions}

1. Altitude has less predictability value for road surface temperature in flat landscapes than in undulating uplands.

2. Thermal mapping results appear to be more inconclusive in flatlands, compared to uplands.

3. It must be ensured that the method was applied correctly, and the results were sound, in order to use the data for road temperature forecasting. Otherwise, temperature difference maps that were made using thermal mapping technique are not recommended for such application due to thermal mapping being more susceptible to errors than computer modelling.

\section{REFERENCES}

Andreescu, M. P., \& Frost, D. B. (1998). Weather and traffic accidents in Montreal, Canada. Climate Research, 9(3), 225-230. https://doi.org/10.3354/cr009225

Bogren, J. (1991). Screening effects on road surface temperature and road slipperiness. Theoretical and applied climatology, 43(1-2), 91-99. https://doi.org/10.1007/BF00865043

Bogren, J., \& Gustavsson, T. (1989). Modelling of local climate for prediction of road slipperiness. Physical Geography, 10(2), 147-164. https://doi.org/10.1080/02723646.1989.10642374

Bogren, J., \& Gustavsson, T. (1991). Nocturnal air and road surface temperature variations in complex terrain. International journal of climatology, 11(4), 443-455. https://doi.org/10.1002/joc.3370110408

Bradley, A. V., Thornes, J. E., Chapman, L., Unwin, D., \& Roy, M. (2002). Modelling spatial and temporal road thermal climatology in rural and urban areas using a GIS. Climate Research, 22(1), 41-55. https://doi.org/10.3354/cr022041

Chapman, L., \& Thornes, J. E. (2006). A geomatics-based road surface temperature prediction model. Science of the Total Environment, 360(1-3), 68-80. https://doi.org/10.1016/j.scitotenv.2005.08.025

Chapman, L., Thornes, J. E., \& Bradley, A. V. (2001b). Modelling of road surface temperature from a geographical parameter database. Part 2: Numerical. Meteorological Applications, 8(4), 421-436. https://doi.org/10.1017/S1350482701004042 
Chapman, L., Thornes, J., \& Bradley, A. (2001a). Modelling of road surface temperature from a geographical parameter database. Part 1: Statistical. Meteorological Applications, 8(4), 409-419. https://doi.org/10.1017/S1350482701004030

Clements, C. B., Whiteman, C. D., \& Horel, J. D. (2003). Cold-air-pool structure and evolution in a mountain basin: Peter Sinks, Utah. Journal of Applied Meteorology, 42(6), 752-768. https://doi.org/10.1175/1520-0450(2003)042\%3C0752:CSAEIA\%3E2.0.C0;2

Cunningham, M. A., Snyder, E., Yonkin, D., Ross, M., \& Elsen, T. (2008). Accumulation of deicing salts in soils in an urban environment. Urban Ecosystems, 11(1), 17-31. https://doi.org/10.1007/s11252-007-0031-x

Fay, L., \& Shi, X. (2012). Environmental impacts of chemicals for snow and ice control: state of the knowledge. Water, Air, \& Soil Pollution, 223(5), 2751-2770. https://doi.org/10.1007/s11270-011-1064-6

Gustavsson, T. (1999). Thermal mapping-a technique for road climatological studies. Meteorological Applications, 6(4), 385-394. https://doi.org/10.1017/S1350482799001334

Gustavsson, T., Karlsson, M., Bogren, J., \& Lindqvist, S. (1998). Development of temperature patterns during clear nights. Journal of applied meteorology, 37(6), 559-571. https://doi.org/10.1175/1520-0450(1998)037<0559:DOTPDC>2.0.CO;2

Hassan, Y., Abd El Halim, A. O., Razaqpur, A. G., Bekheet, W., \& Farha, M. H. (2002). Effects of runway deicers on pavement materials and mixes: comparison with road salt. Journal of transportation engineering, 128(4), 385-391. https://doi.org/10.1061/(ASCE)0733-947X(2002)128:4(385)

Howard, K. W., \& Haynes, J. (1993). Groundwater contamination due to road de-icing chemicals-salt balance implications. Geoscience Canada, 20(1). Retrieved from https://journals.lib.unb.ca/index.php/GC/article/view/3784

Hu, Y., Almkvist, E., Lindberg, F., Bogren, J., \& Gustavsson, T. (2016). The use of screening effects in modelling route-based daytime road surface temperature. Theoretical and Applied Climatology, 125(1-2), 303-319. https://doi.org/10.1007/s00704-015-1508-9

Kiefer, M. T., \& Zhong, S. (2015). The role of forest cover and valley geometry in cold-air pool evolution. Journal of Geophysical Research: Atmospheres, 120(17), 8693-8711. https://doi.org/10.1002/2014JD022998

Mirzanamadi, R., Johansson, P., \& Grammatikos, S. A. (2018). Thermal properties of asphalt concrete: A numerical and experimental study. Construction and Building Materials, 158, 774-785. https://doi.org/10.1016/j.conbuildmat.2017.10.068

Norrman, J., Eriksson, M., \& Lindqvist, S. (2000). Relationships between road slipperiness, traffic accident risk and winter road maintenance activity. Climate Research, 15(3), 185-193. https://doi.org/10.3354/cr015185

Shao, J., \& Lister, P. J. (1995). Data filtering for thermal mapping of road surface temperatures. Meteorological Applications, 2(2), 131-135.

https://doi.org/10.1002/met.5060020206
Thermal Mapping

in Flat Lowlands

and Undulating

Uplands -

a Comparison

of Results 
Shao, J., Lister, P. J., Hart, G. D., \& Pearson, H. B. (1996). Thermal mapping: reliability and repeatability. Meteorological Applications, 3(4), 325-330. https://doi.org/10.1002/met.5060030405

Shao, J., Swanson, J. C., Patterson, R., Lister, P. J., \& McDonald, A. N. (1997). Variation of winter road surface temperature due to topography and application of thermal mapping. Meteorological Applications, 4(2), 131-137. https://doi.org/10.1017/S135048279700042X

Thornes, J. E. (1991). Thermal mapping and road-weather information systems for highway engineers. Highway meteorology, 39-67.

Usman, T., Fu, L., \& Miranda-Moreno, L. F. (2010). Quantifying safety benefit of winter road maintenance: Accident frequency modeling. Accident Analysis \& Prevention, 42(6), 1878-1887. https://doi.org/10.1016/j.aap.2010.05.008

Vitasse, Y., Klein, G., Kirchner, J. W., \& Rebetez, M. (2017). Intensity, frequency and spatial configuration of winter temperature inversions in the closed La Brevine valley, Switzerland. Theoretical and applied climatology, 130(3-4), 1073-1083. https://doi.org/10.1007/s00704-016-1944-1

Vosper, S. B., \& Brown, A. R. (2008). Numerical simulations of sheltering in valleys: the formation of nighttime cold-air pools. Boundary-layer meteorology, 127(3), 429-448. https://doi.org/10.1007/s10546-008-9272-3

Whiteman, C. D., Haiden, T., Pospichal, B., Eisenbach, S., \& Steinacker, R. (2004). Minimum temperatures, diurnal temperature ranges, and temperature inversions in limestone sinkholes of different sizes and shapes. Journal of applied meteorology, 43(8), 1224-1236. https://doi.org/10.1175/1520-0450(2004)043\%3C1224:MTDTRA\%3E2.0.CO;2

Whiteman, C. D., Zhong, S., Shaw, W. J., Hubbe, J. M., Bian, X., \& Mittelstadt, J. (2001). Cold pools in the Columbia Basin. Weather and Forecasting, 16(4), 432-447.

https://doi.org/10.1175/1520-0434(2001)016<0432:cpitcb>2.0.co;2 